\title{
Effect of Amount of Carbon on the Reduction Efficiency of Iron Ore-Coal Composite Pellets in Multi-layer Bed Rotary Hearth Furnace (RHF)
}

\author{
SRINIBASH MISHRA and GOUR GOPAL ROY
}

The effect of carbon-to-hematite molar ratio has been studied on the reduction efficiency of iron ore-coal composite pellet reduced at $1523 \mathrm{~K}\left(1250{ }^{\circ} \mathrm{C}\right)$ for 20 minutes in a laboratory scale multi-layer bed rotary hearth furnace (RHF). Reduced pellets have been characterized through weight loss measurement, estimation of porosity, shrinkage, qualitative and quantitative phase analysis by XRD. Performance parameters such as the degree of reduction, metallization, carbon efficiency, productivity, and compressive strength have been calculated to compare the process efficacy at different carbon levels in the pellets. Pellets with optimum carbon-to-hematite ratio $\left(\mathrm{C} / \mathrm{Fe}_{2} \mathrm{O}_{3}\right.$ molar ratio $\left.=1.66\right)$ that is much below the stoichiometric carbon required for direct reduction of hematite yielded maximum reduction, better carbon utilization, and productivity for all three layers. Top layer exhibited maximum reduction at comparatively lower carbon level $\left(\mathrm{C} / \mathrm{Fe}_{2} \mathrm{O}_{3}\right.$ molar ratio $\left.<2.33\right)$ in the pellet, while bottom layer exceeded top layer reduction at higher carbon level $\left(\mathrm{C} / \mathrm{Fe}_{2} \mathrm{O}_{3}\right.$ molar ratio >2.33). Correlation between degree of reduction and metallization indicated non-isothermal kinetics influenced by heat and mass transfer in multi-layer bed RHF. Compressive strength of the partially reduced pellet with optimum carbon content $\left(\mathrm{C} / \mathrm{Fe}_{2} \mathrm{O}_{3}\right.$ molar ratio $\left.=1.66\right)$ showed that they could be potentially used as an alternate feed in a blast furnace or any other smelting reactor.

DOI: $10.1007 / \mathrm{s} 11663-016-0666-1$

(c) The Minerals, Metals \& Materials Society and ASM International 2016

\section{INTRODUCTION}

IRONMAKING using RHF process has drawn attention of the researchers for the last couple of decades. The use of low-grade ore, non-coking coal fines, and lower $\mathrm{CO}_{2}$ emission has driven particular attention to this process. The intimacy of iron oxide and reductant improves the mass transfer efficacy and efficient carbon utilization. The RHF-based processes suffer from low productivity due to heat transfer limitation that restricts a few layers on the hearth. Therefore, the broad objective of our research has been toward the study of reduction efficiency of iron ore-coal composite pellets in multi-layer bed RHF. The present article specifically focuses on the effect of carbon content in the pellet on the reduction efficiency in such pellet bed.

Several fundamental investigations have been reported on the reduction kinetics of ore-coal composite pellets, which are, however, mostly limited to reduction of single composite pellet or mixtures of iron ore and coal fines in small scale (few grams). Many researchers ${ }^{[1-7]}$ have shown that increasing the amount of carbon

SRINIBASH MISHRA, Research Scholar, and GOUR GOPAL ROY, Professor and Head of the Department, are with the Department of Metallurgical and Materials Engineering, Indian Institute of Technology Kharagpur, Kharagpur, West Bengal 721302, India. Contact e-mail: srinibashm21@gmail.com

Manuscript submitted December 17, 2015.

Article published online April 8, 2016. content relative to iron oxide content in the pellet monotonically increases the reduction rate at around $1273 \mathrm{~K}\left(1000^{\circ} \mathrm{C}\right)$. While others ${ }^{[8-10]}$ have also reported that increasing the carbon content above the stoichiometric value has no significant effect on the degree of reduction above $1473 \mathrm{~K}\left(1200{ }^{\circ} \mathrm{C}\right)$. It is well reported that at comparatively lower temperature, carbon gasification is the rate-controlling step during the initial stages of reduction that shifts toward wustite reduction during the later stage of reduction. ${ }^{[3]}$ Freshly produced iron at the later stages of reduction is supposed to catalyze the carbon gasification and increase the rate of carbon oxidation by several orders. ${ }^{[1]}$ At higher temperature, the kinetics becomes mixed controlled both by carbon gasification and wustite reduction. ${ }^{[12]}$ The volatiles of coal play a significant role in the reduction of ore-coal composites. However, Wang et al. ${ }^{[13]}$ reported a negligible effect of volatiles on the extent of reduction during fast heating. Huang et al..$^{[14]}$ studied the effect of volatiles on the carbothermic reduction of ore-coal composite pellets in a tall bed hearth furnace. They reported higher metallization in the top layer as compared to the lower layers in the case of coal with low volatile content, while higher metallization in bottom layer as compared to upper layers in the case of coal with higher volatile content. Sohn and Freuhan ${ }^{[15]}$ studied the effect of volatiles on the reduction kinetics of iron oxide-coal composite pellet in a laboratory-simulated multi-layer RHF heated with an infrared lamp. They reported a negligible reduction in composite pellets during its devolatilization, but the volatiles evolved 
could be potentially utilized for the reduction of subsequent layers. Similarly, Halder and Freuhan ${ }^{[16]}$ studied the effect of pellet shrinkage on heat transfer in a multi-layer bed RHF simulator. They reported that the extent of external heat transfer could be enhanced by six times to the bottom layers when the top layer pellets are reduced 30 pct by size.

Based on the above literature, it is observed that although several studies have been reported on single composite pellet or mixture, very limited literature has been published depicting the layer-wise analysis and the effect of relevant parameters on the reduction behavior of iron ore-coal composite pellets in multi-layer bed RHF. The amount of carbon in the composite pellet is an important parameter as it influences the extent of in situ carbon gasification, corresponding heat absorption, reduction, and carbon utilization, which in turn depend on heat and mass transfer and subsequently bed parameters in multi-layer bed RHF. Therefore, the present study aims at investigating the effect of carbon content in the composite pellet on the reduction efficiency of iron ore-coal composite pellets layer-wise in multi-layered bed RHF and their suitability for the use as an alternate feed in a blast furnace or any other smelting reactor.

\section{EXPERIMENTAL}

\section{A. Raw Materials}

The raw materials used in the present study are iron ore and coal fines obtained from RDCIS Ranchi, India. The chemical composition of the raw materials used is provided in Tables I, II, and III.

\section{B. Pellet Preparation}

Iron ore and coal fines (both $-150 \mu \mathrm{m}$ ) with a small amount of bentonite powder ( $3 \mathrm{wt}$ pct) are thoroughly mixed in a rotating glass bottle for 8 to 10 hours.
Distilled water is added, and pellets (16 $\mathrm{mm}$ size) of different compositions are prepared by hand rolling. The green pellets are air dried for 48 hours and subsequently dried at $473 \mathrm{~K}\left(200{ }^{\circ} \mathrm{C}\right)$ for 2 hours to remove the physical moisture from the pellets and get the strength after curing.

\section{Reduction in $\mathrm{RHF}$}

The dried pellets are packed in three layers in separate SiC-graphite (35 wt pct graphite) crucibles and are reduced in an electrically heated laboratory scale RHF at $1523 \mathrm{~K}\left(1250{ }^{\circ} \mathrm{C}\right)$ for 20 minutes. The SiC-graphite crucible used is the cylindrical with outer diameter 90-mm, 10-mm thick, and 60-mm height. Although SiC-graphite crucible conducts heat and introduces undesirable heat fluxes from the side and bottom walls of the crucible, such crucible is used because of its high resistance to thermal shock and it is found not to develop any cracks with the heating rates used in the RHF. The effect of undesirable heat fluxes from side walls has been compensated by considering pellets from the central region and excluding the peripheral pellets for the characterization of a particular layer. Effect of bottom heat flux has also been partially restricted by using a layer of alumina balls on the bottom of crucible wall. Initially, some runs with empty crucibles are made to check any weight loss due to initial moisture and carbon. After two empty runs, the crucibles are found not to loose any weight and then used for experiments. The reduced pellets are marked as the top layer (TL), the middle layer (ML), and the bottom layer (BL) depending on their position along the height. The arrangement of pellets in the crucible is shown in Figure 1.

The RHF used for the present experiments is shown in Figure 2, while Figure 2(a) shows a photograph of the RHF, Figure 2(b) depicts the temperature and the residence time of the pellets in various zones. It is heated electrically from the side by $\mathrm{MoSi}_{2}$ heating elements. The RHF has an outer diameter of $1.93 \mathrm{~m}$, inner

Table I. Chemical Composition of Iron Ore (Mass Pet)

\begin{tabular}{lcccccc}
\hline $\mathrm{Fe}_{2} \mathrm{O}_{3}$ & $\mathrm{SiO}_{2}$ & $\mathrm{CaO}$ & $\mathrm{P}_{2} \mathrm{O}_{5}$ & $\mathrm{MnO}$ & $\mathrm{Al}_{2} \mathrm{O}_{3}$ & LOI (Loss on Ignition) \\
\hline 94.71 & 2.77 & 0.05 & 0.05 & 0.02 & 0.62 & 1.9 \\
\hline
\end{tabular}

Table II. Coal Composition

\begin{tabular}{|c|c|c|c|c|c|c|c|c|c|c|}
\hline \multicolumn{4}{|c|}{ Proximity Analysis of Coal (Mass Pct) } & \multicolumn{7}{|c|}{ Ash Composition (Mass Pct) } \\
\hline $\mathrm{FC}$ & $\mathrm{VM}$ & Ash & Moisture & $\mathrm{SiO}_{2}$ & $\mathrm{Al}_{2} \mathrm{O}_{3}$ & $\mathrm{CaO}$ & $\mathrm{Na}_{2} \mathrm{O}$ & $\mathrm{Fe}_{2} \mathrm{O}_{3}$ & $\mathrm{TiO}_{2}$ & $\mathrm{~K}_{2} \mathrm{O}$ \\
\hline 68.2 & 24.3 & 6.8 & 0.7 & 48.1 & 30.6 & 1.94 & 1.38 & 8.86 & 2.12 & 1 \\
\hline
\end{tabular}

Table III. Chemical Composition of Bentonite (Mass Pct)

\begin{tabular}{lccccccc}
\hline $\mathrm{SiO}_{2}$ & $\mathrm{Al}_{2} \mathrm{O}_{3}$ & $\mathrm{CaO}$ & $\mathrm{MgO}$ & $\mathrm{Na}_{2} \mathrm{O}$ & $\mathrm{Fe}_{2} \mathrm{O}_{3}$ & $\mathrm{TiO}_{2}$ & $\mathrm{~K}_{2} \mathrm{O}$ \\
\hline 58.3 & 17.47 & 0.93 & 2.05 & 5.89 & 9.55 & 1.81 & 1.07 \\
\hline
\end{tabular}




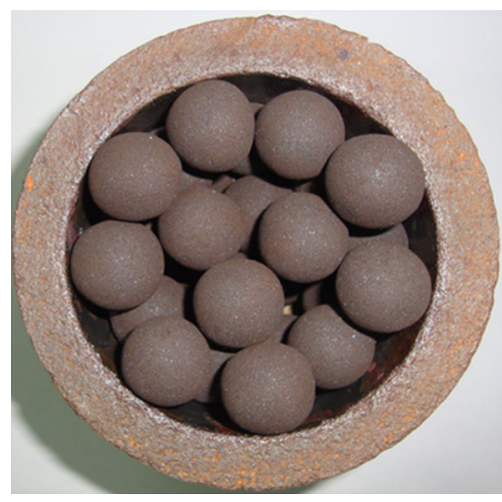

Fig. 1-Pellet arrangement in the crucible.
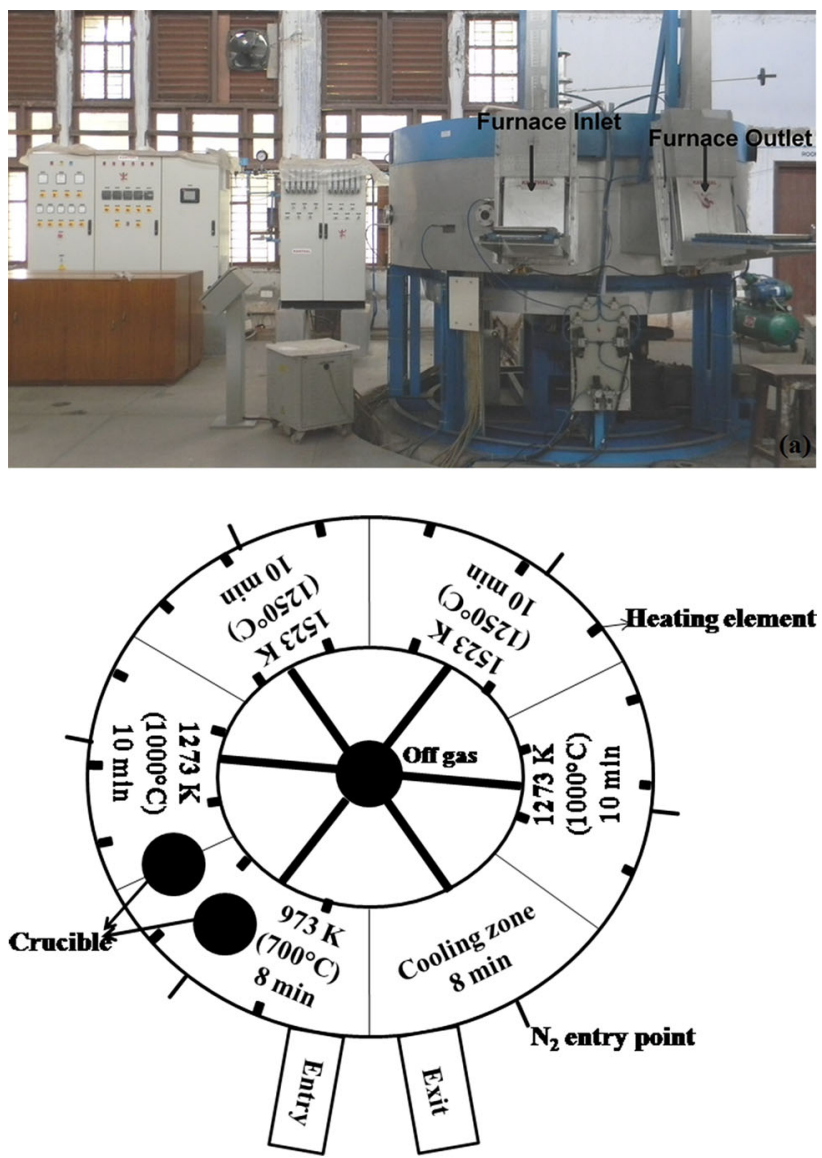

(b)

Fig. 2-Rotary Hearth Furnace at Steel Technology Centre, IIT Kharagpur, India. (a) Photograph (b) schematic representation of various zones with time, temperature, location of heating element, and crucible.

diameter of $1.25 \mathrm{~m}$, and height of $0.5 \mathrm{~m}$. The width of the hearth is $0.2 \mathrm{~m}$ and hearth height is $0.18 \mathrm{~m}$. The hearth is water-sealed to prevent the leakage of gases during and after reduction from the bottom of the furnace. There are six different temperature zones namely preheating/pre-reduction, reduction, and cooling zone. The time period of the hearth revolution is controlled by a variable frequency drive attached to the furnace varying from 28 to 56 minutes. In the present experiments, the time period for hearth revolution from entry to the exit end of the sample is maintained at 56 minutes and the reduction time at 20 minutes. The average temperature maintained at various zones is as follows: Zone $1 \rightarrow 973 \mathrm{~K}\left(700{ }^{\circ} \mathrm{C}\right)$; Zone $2 \rightarrow$ $1273 \mathrm{~K}\left(1000{ }^{\circ} \mathrm{C}\right)$; Zone $3 \rightarrow 1523 \mathrm{~K}\left(1250^{\circ} \mathrm{C}\right)$; Zone 4 $\rightarrow 1523 \mathrm{~K}\left(1250{ }^{\circ} \mathrm{C}\right)$; Zone $5 \rightarrow 1273 \mathrm{~K}\left(1000{ }^{\circ} \mathrm{C}\right)$; and Zone $6 \rightarrow$ cooling zone (Figure 2(b)). Nitrogen gas is passed into the furnace 5 minutes before the beginning of experiments at a rate of $5 \mathrm{~L} /$ minute to flush out any air present in the furnace. A constant flow of nitrogen is also maintained in all zones at a rate of $5 \mathrm{~L} /$ minute during preheating/pre-reduction, and reduction to maintain an inert atmosphere and $5 \mathrm{~L} /$ minute in cooling zone till the temperature reaches $673 \mathrm{~K}\left(400{ }^{\circ} \mathrm{C}\right) . \mathrm{N}_{2}$ gas is passed during reduction as well as during cooling to maintain an inert atmosphere to prevent the re-oxidation of the already reduced iron oxide. Since we are dealing with small mass and the furnace is not airtight, without nitrogen injection the atmosphere consists mostly of air and chance of re-oxidation is more. In contrast, in a gas-fired commercial furnace, since the reduction of large mass takes place the $\mathrm{CO}$ generated from direct reduction is large that keeps the furnace condition reducing. Besides in a gas-fired furnace, a positive pressure exists in the hearth that restricts the air ingression.

After the samples come out of the furnace after cooling, the pellets are collected layer-wise from the central region of each layer for subsequent characterization and analysis.

\section{Characterization of Reduced Pellets}

The porosity of the pellets has been measured following Archimedes' principles. Initially, the weight of the dry pellet $(D)$ is measured. Then, the pellet is soaked in isopropyl alcohol for 2 hours and the weight of the soaked pellet suspended in isopropyl alcohol $(S)$ is measured. The wet weight of the wet pellet $(W)$ is also measured after wiping the excess alcohol from the surface of the pellet. Finally, the porosity has been estimated using the following equation involving $D, S$, and $W$.

$$
\text { Porosity (pct) }=\frac{W-D}{W-S} \times 100 \text {. }
$$

The volumetric shrinkage of the reduced pellets is measured from the change in volume before and after reduction. Since the pellets are hand rolled, they are not completely spherical in nature. Thus, the diameter of the pellets is measured at six different locations and the average diameter is taken for the calculation.

$$
\text { Shrinkage }(\mathrm{pct})=\frac{V_{\mathrm{o}}-V_{\mathrm{f}}}{V_{\mathrm{o}}} \times 100,
$$

where $V_{\mathrm{o}}$ is the volume of the pellet before reduction and $V_{\mathrm{f}}$ is the volume after reduction. 
The extent of removal of oxygen from the composite pellets is characterized by degree of reduction (pct), which is defined as follows:

Degree of reduction (pct)

$$
=\frac{\text { Weight of oxygen removed }}{\text { Weight of removable oxygen in iron oxide }} \times 100 \text {. }
$$

Weight of oxygen removed $=$ total weight loss - carbon loss - VM loss - LOI of iron ore.

Total weight loss is measured by noting the difference in weight of the pellets before and after reduction. The carbon loss is estimated by deducting the amount of residual carbon in reduced pellet from the initial carbon in the unreduced pellets. The initial carbon is estimated from the fixed carbon in the coal. The residual carbon in the reduced pellet is measured using Strohlein apparatus where the unutilized carbon is completely burned to gas and gas volume is measured for subsequent calculation of residual carbon in the reduced pellets. Total removable oxygen is calculated as the total oxygen associated only with hematite in the unreduced pellets.

The metallic iron content in the reduced sample has been analyzed through chemical analysis. ${ }^{[17]}$ The degree of metallization has been estimated as

$$
\text { Degree of metallization (pct) }=\frac{\mathrm{Fe}_{\mathrm{M}}}{\mathrm{Fe}_{\mathrm{T}}} \times 100,
$$

where $\mathrm{Fe}_{\mathrm{M}}$ is the metallic iron and $\mathrm{Fe}_{\mathrm{T}}$ is the total iron in the reduced mass.

The various phases present in the reduced sample have been identified by XRD analysis performed on a BRUKER ADVANCED 800 X-ray Diffractometer. During the test, Cobalt target with Nickel filter and the step size of $0.02 \mathrm{deg}$ and a time step of 0.3 second has been used. The qualitative phase analysis has been performed using X'Pert HighScore software and phase quantification by TOPAS (Total Pattern Analysis Solution) software.

\section{RESULTS AND DISCUSSION}

The Degree of Reduction (DOR) and Degree of Metallization (DOM) estimated and presented in this article are tabulated in Table IV.

Figure 3 depicts a correlation between DOR and DOM, where a stoichiometric line (shown as dotted line) correlating DOR and DOM has also been superimposed on it. Experimental line (shown as the solid line) represents the best fit line through experimental data. A hypothetical data at $(100,100)$ has been added to force the line to pass through the $(100,100)$ point. It is to be noted that the line indeed very closely passes through the $(100,100)$ point with a correlation coefficient at 92 pct. The stoichiometric line represents a situation when the sample undergoes uniform and isothermal reduction. But the reduction of pellets is non-isothermal and non-uniform across its radius. Since wustite is the lowest order among the possible iron oxide phases that
Table IV. Layer-Wise DOR and DOM for Pellet

\begin{tabular}{|c|c|c|c|c|}
\hline \multicolumn{5}{|c|}{ S. No. Layer C to $\mathrm{Fe}_{2} \mathrm{O}_{3}$ Mola } \\
\hline 1 & TL & 1.33 & 67.5 & 52.6 \\
\hline 2 & ML & & 61.2 & 47.7 \\
\hline 3 & BL & & 61.5 & 55.6 \\
\hline 4 & TL & 1.66 & 75.3 & 61.8 \\
\hline 5 & ML & & 73.1 & 61.3 \\
\hline 6 & $\mathrm{BL}$ & & 74.1 & 66.2 \\
\hline 7 & TL & 2 & 72.4 & 57.7 \\
\hline 8 & ML & & 67.2 & 56.3 \\
\hline 9 & BL & & 70.7 & 63 \\
\hline 10 & TL & 2.33 & 69.3 & 54.8 \\
\hline 11 & ML & & 64.3 & 52.9 \\
\hline 12 & BL & & 65.4 & 58.9 \\
\hline 13 & TL & 2.66 & 58.9 & 42.8 \\
\hline 14 & ML & & 56.8 & 41.8 \\
\hline 15 & $\mathrm{BL}$ & & 63.3 & 55.8 \\
\hline 16 & $\mathrm{TL}$ & 3 & 50.4 & 41.9 \\
\hline 17 & ML & & 44 & 32 \\
\hline 18 & BL & & 60 & 53.9 \\
\hline
\end{tabular}
of Different $\mathrm{C} / \mathrm{Fe}_{2} \mathrm{O}_{3}$ Molar Ratios

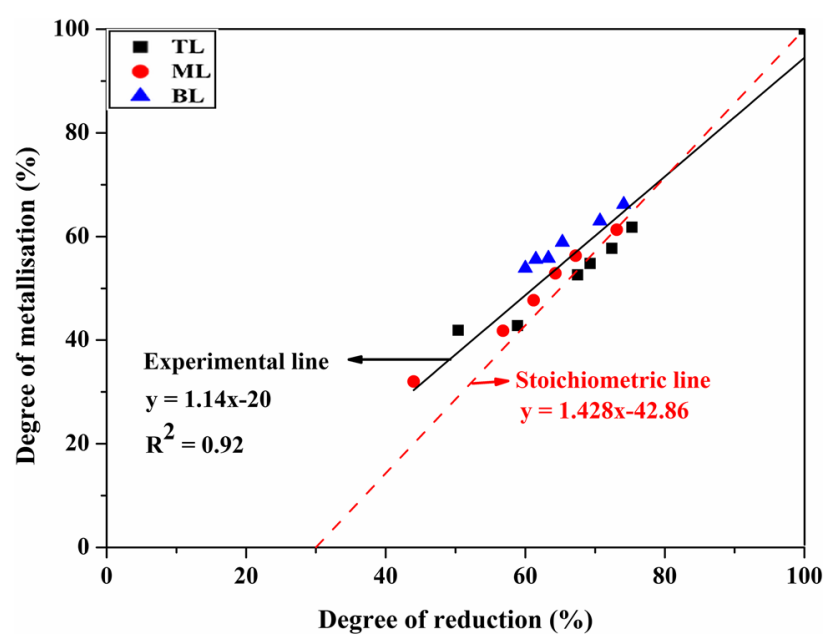

Fig. 3-Correlation between DOR and DOM $\left(1523 \mathrm{~K}\left(1250{ }^{\circ} \mathrm{C}\right)\right.$, 20 minute)).

contain 70 pet oxygen, stoichiometrically beyond 30 pct DOR, metallic iron will form. The experimental line is found to intercept the percent degree of reduction line much below $30 \mathrm{pct}$ on extrapolation. This may be attributed to inhomogeneous reduction, i.e., when the surface of the pellet is metallized, the interior may not. Thus, metallic iron may form when the average DOR is even less than 30 pct. This clearly indicates that the reduction process in the composite pellet is non-isothermal and heat and mass transfer controlled especially in multi-layer bed RHF.

\section{A. Optimum $\mathrm{C} / \mathrm{Fe}_{2} \mathrm{O}_{3}$ molar ratio}

Experiments are conducted using pellets containing different $\mathrm{C} / \mathrm{Fe}_{2} \mathrm{O}_{3}$ molar ratios to optimize the internal 
carbon content of pellets for maximum reduction efficiency. $\mathrm{C} / \mathrm{Fe}_{2} \mathrm{O}_{3}$ molar ratio is varied from 1.33 to maximum of 3 , the stoichiometric carbon required for direct reduction of hematite to iron. The dried pellets are reduced in three-layered bed at RHF at $1523 \mathrm{~K}$ $\left(1250{ }^{\circ} \mathrm{C}\right)$ for 20 minutes. It may be noted that the pellets stay in the preheating zones at $973 \mathrm{~K}, 1273 \mathrm{~K}$ $\left(700{ }^{\circ} \mathrm{C}, 1000{ }^{\circ} \mathrm{C}\right)$ for another 10 minutes each. However, since carbon gasification is sluggish below $1273 \mathrm{~K}$ $\left(1000{ }^{\circ} \mathrm{C}\right)$, in situ generation of $\mathrm{CO}$ will not be significant below $1273 \mathrm{~K}\left(1000{ }^{\circ} \mathrm{C}\right)$ leading to a poor kinetics. Besides, the pellet will take some time to preheat to 1273 $\mathrm{K}\left(1000^{\circ} \mathrm{C}\right)$ when the reduction becomes significant. Therefore, it is likely that when the pellet enters the reduction zone after traversing through the preheat zone at $1273 \mathrm{~K}\left(1000{ }^{\circ} \mathrm{C}\right)$, it will attend $1273 \mathrm{~K}\left(1000{ }^{\circ} \mathrm{C}\right)$ throughout and be ready for reduction. Therefore, only partial reduction of higher oxide phases like hematite, magnetite that requires less $\mathrm{CO}$ might take place in the preheating/pre-reduction zone. But majority of oxygen will be removed in the reduction zone. Therefore, the credit has been given to the reduction zone. The layer-wise variation of the degree of reduction with the change in the $\mathrm{C} / \mathrm{Fe}_{2} \mathrm{O}_{3}$ molar ratio in pellets is shown in Figure 4.

It is observed that the degree of reduction first increases with increase in $\mathrm{C} / \mathrm{Fe}_{2} \mathrm{O}_{3}$ molar ratio and reaches its maximum at the ratio of 1.66 and then extent of reduction decreases with further increase in molar ratio beyond 1.66. Thus, there exists an optimum carbon level inside the pellet at which reduction becomes maximum and after that it decreases significantly with increase in the carbon inside the pellet. It is further interesting to note that this optimum level of carbon is much below that is required stoichiometrically to reduce hematite by direct reduction. These observations are evident in all three layers in the pellet bed. Many researchers have reported that the degree of reduction increases with the increase in internal carbon content even above the stoichiometric value in small mass systems like small single pellet, mixture, etc. ${ }^{[1-7]}$ In such

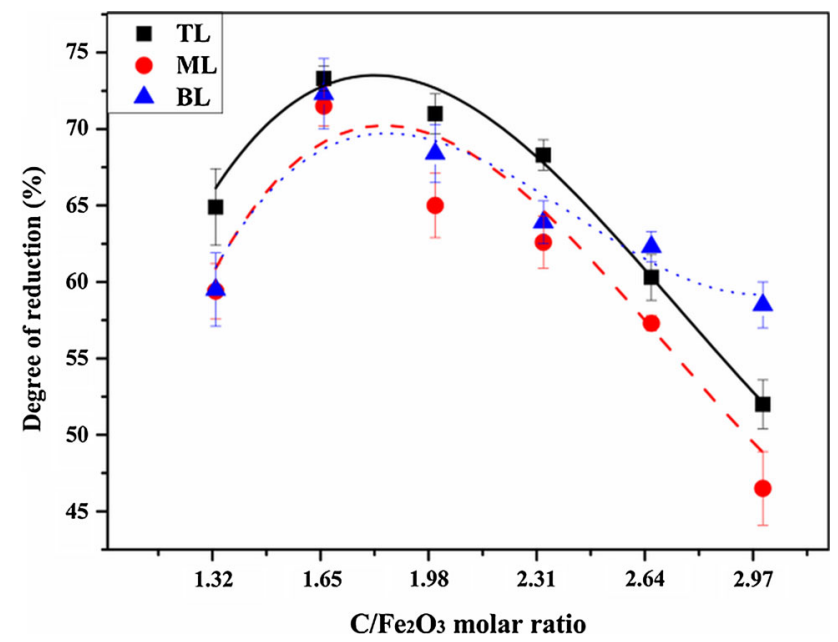

Fig. 4-Layer-wise variation of degree of reduction for different $\mathrm{C} /$ $\mathrm{Fe}_{2} \mathrm{O}_{3}$ molar ratio in pellets. small mass systems, the effect of heat and mass transfer is not very significant. The present experiment demonstrates that carbon even less than the stoichiometric value for direct reduction of hematite produced higher extent of reduction in multi-layer bed RHF. Lower carbon restricts carbon gasification and promotes indirect reduction by utilizing the $\mathrm{CO}$ produced by direct reduction that tends to shift the final gaseous product from $\mathrm{CO}$ to $\mathrm{CO}, \mathrm{CO}_{2}$ mixture and therefore making the process more carbon efficient. In such case, $\mathrm{CO}$ will be utilized partially and in the extreme case completely following the overall reaction when the product is $\mathrm{CO}_{2}$ : $\mathrm{Fe}_{2} \mathrm{O}_{3}+1.5 \mathrm{C}=2 \mathrm{Fe}+1.5 \mathrm{CO}_{2}$ and can attain lowest stoichiometric $\mathrm{C} / \mathrm{Fe}_{2} \mathrm{O}_{3}$ molar ratio of 1.5. Our experiment also indicates an optimum ratio at 1.66 which is very close to 1.5 , indicating significant $\mathrm{CO}$ utilization could be achieved at lower carbon level in the pellet that is much below the stoichiometric carbon required for direct reduction of hematite.

\section{B. Effect of coal content on the porosity of the pellets}

As the carbon content is increased, the volatile matter associated with the pellet is also increased. These volatile matters get escaped at around $773 \mathrm{~K}\left(500{ }^{\circ} \mathrm{C}\right)$, which produces porosity and formation of the crack in the pellet. The porosity of reduced pellets from top layer with the variation in carbon content is shown in Figure 5.

The internal porosity of the reduced pellet increased significantly with the increase in carbon content. The photographs of reduced pellets from the top layer with the variation in carbon content are shown in Figure 6. These figures distinctly demonstrate that cracks in the pellet increase with increase in the amount of carbon inside the pellet; the fact that is also reported in the literature. ${ }^{[18]}$

The presence of cracks makes the pellet more open to atmosphere and allows product gases $\left(\mathrm{CO}\right.$ and $\left.\mathrm{CO}_{2}\right)$ to pass away easily to the atmosphere without further participation in the reduction process, which may be attributed for the lower level of reduction at the top

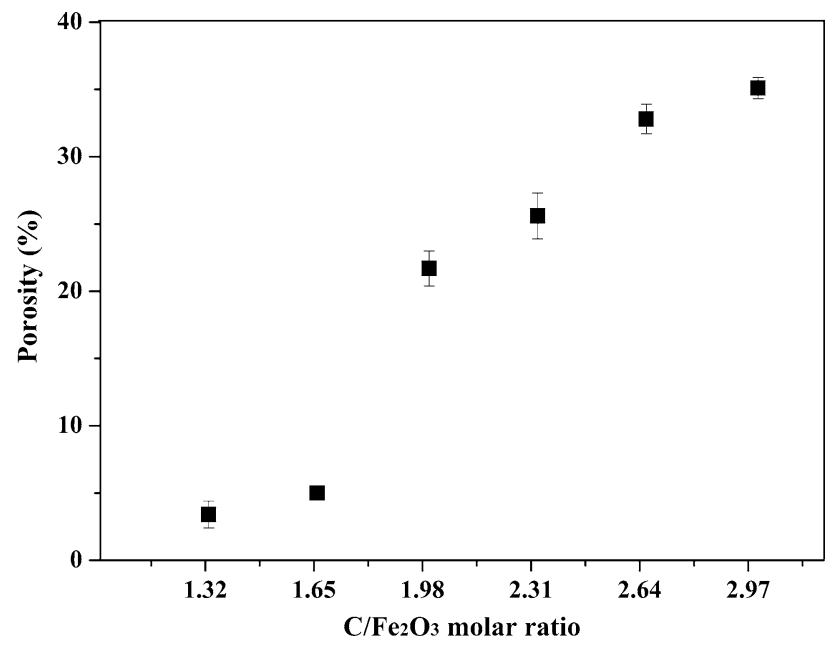

Fig. 5-Extent of porosity in the partially reduced pellets at the top layer for different $\mathrm{C} / \mathrm{Fe}_{2} \mathrm{O}_{3}$ molar ratios. 


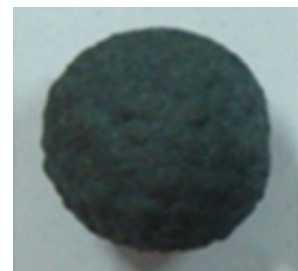

(a)

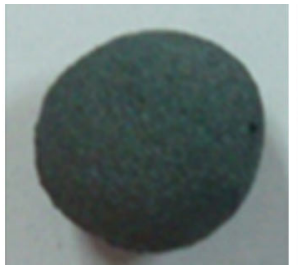

(b)

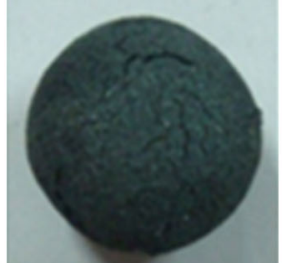

(c)

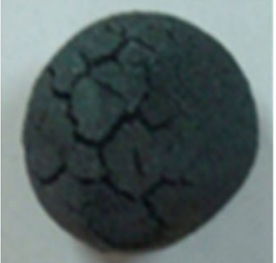

(d)

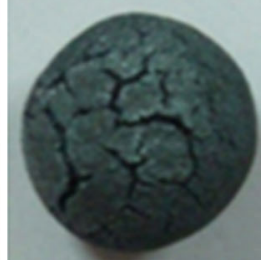

(e)

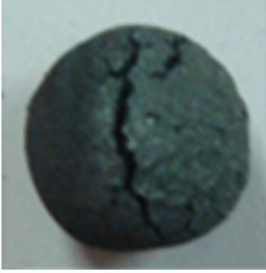

(f)

Fig. 6-Photographs of reduced pellet from top layer with $\mathrm{C} / \mathrm{Fe}_{2} \mathrm{O}_{3}$ molar ratio of $(a)$ 1.33, (b) 1.66, (c) 2, (d) 2.33, (e) 2.66, (f) 3.

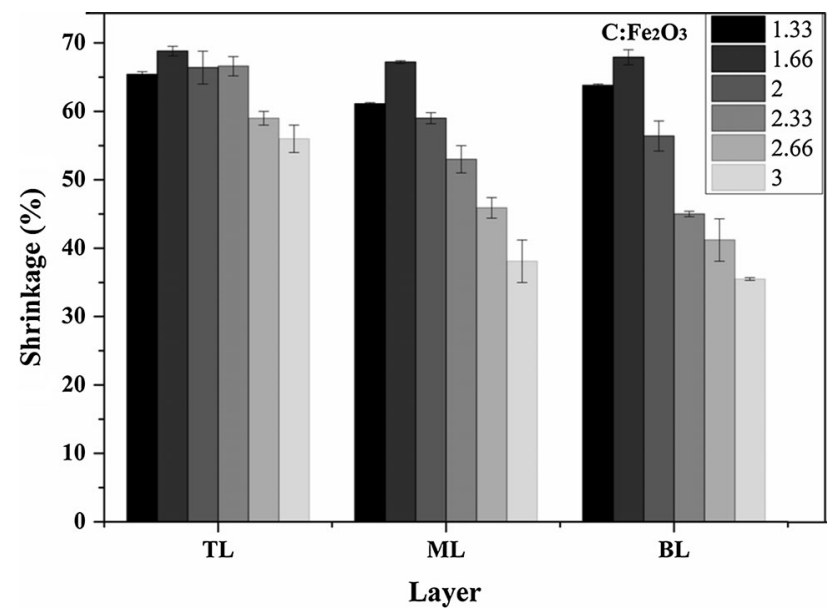

Fig. 7-Layer-wise shrinkage of pellets with different $\mathrm{C} / \mathrm{Fe}_{2} \mathrm{O}_{3}$ molar ratios.

layer for high carbon level in the pellet. Besides, the formation of cracks disturbs the physical integrity of the pellet and subsequently hampers the internal heat transfer. Furthermore, increase in porosity reduces the thermal conductivity of the pellet significantly, ${ }^{[19]}$ thereby affecting the heat transfer in the pellet and restricting the endothermic reduction process. Besides, higher carbon promotes more endothermic carbon gasification reaction and consequently makes heat deficiency in the pellet. ${ }^{[9]}$

\section{Layer-wise effect}

From Figure 4, it is further observed that relative extent of reduction is the highest in the top layer followed by the bottom layer and it is the lowest for the middle layer in the case of pellets with carbon-to-hematite molar ratio less than 2.33. General conviction suggests that top layer will be reduced more as it directly receives the heat from the top, while the bottom will reduce least as it receives heat from top indirectly being shielded by middle and top layers. However since the bottom layer stands on conducting crucible separated by a single alumina layer, heat is also received from the bottom wall of crucible by radiation. The middle layer receives the minimum heat being shielded from the heat sources at the top and bottom. Furthermore, it is also observed that in the case of the composite pellet with carbon level greater than $\mathrm{C} / \mathrm{Fe}_{2} \mathrm{O}_{3}$ of 2.33 , the bottom layer showed higher degree of reduction as compared to the top layer and middle layer being the lowest as usual.
Huang et al. ${ }^{[14]}$ also indicated higher extent of reduction at the lower layer compared to top layer in a tall bed hearth furnace.

Such switch from top to bottom layer for higher reduction might be attributed as follows:

1. As discussed in Section III-B, it is found that the top surface is cracked with high carbon-containing pellet that allows $\mathrm{CO}, \mathrm{CO}_{2}$ gases to pass to the atmosphere easily without further participation in the reaction. This reduces the extent of reduction at the top layer.

2. The volatiles in coal are released at around $773 \mathrm{~K}$ $\left(500{ }^{\circ} \mathrm{C}\right)$, while reduction of iron ore takes place at much higher temperature (say $1173 \mathrm{~K}\left(900{ }^{\circ} \mathrm{C}\right.$ ) and above). Therefore, unless the escape of volatile is restricted, it is more likely that the volatile will escape without participating in the reduction reactions. In a top-heated furnace, there exists an unfavorable temperature gradient for the escape of volatile generated at the bottom of the furnace that is comparatively cooler and heavier. Therefore, in the bed, the volatile generated at the bottom would like to reside for longer duration and participate in the reduction reaction that might lead to the higher extent of reduction at the bottom especially for pellets containing high carbon with comparatively lower thermal conductivity.

3. Another reason may be because temperature gradient within the pellet at the bottom of the bed will be higher compared to that at the top especially for high carbon-containing pellets. Thus, it might happen that when the volatile is released from the center of the pellet, the surface has attained the reduction temperature. This leads to participation of volatile in the reduction process at the bottom of the bed and consequently higher extent of reduction. Besides, the hydrogen of volatile is more efficient than $\mathrm{CO}$ both thermodynamically and kinetics wise, and therefore under favorable condition, volatile will react faster than carbon.

\section{Shrinkage}

The layer-wise shrinkage of the reduced pellets for different $\mathrm{C} / \mathrm{Fe}_{2} \mathrm{O}_{3}$ molar ratios is shown in Figure 7 .

The maximum shrinkage is observed with the $\mathrm{C} /$ $\mathrm{Fe}_{2} \mathrm{O}_{3}$ molar ratio of 1.66 for all three layers, which is consistent with the maximum reduction obtained for this carbon level. This may be attributed for the following three reasons: (1) Higher the DOR, higher is the gas removal from the pellet that favors shrinkage. (2) At low carbon level, the conductivity of the pellets is 


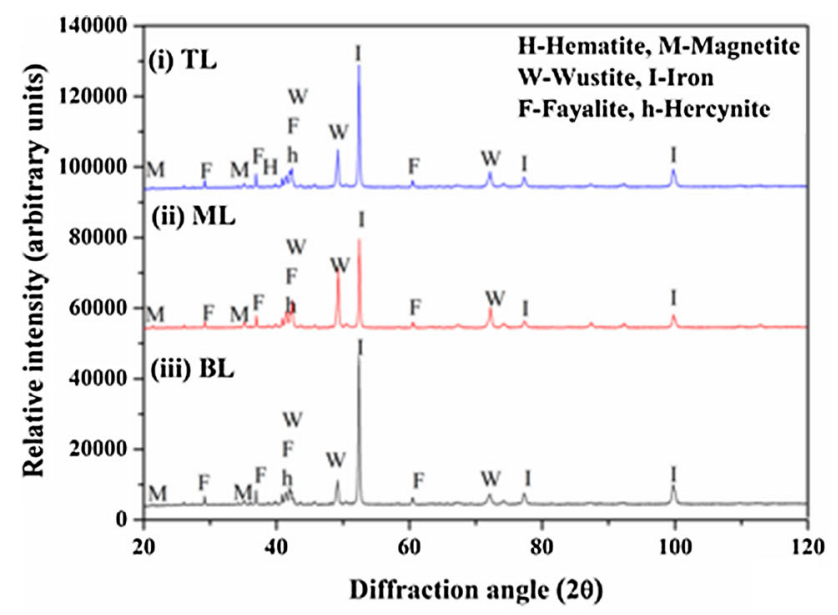

(a)

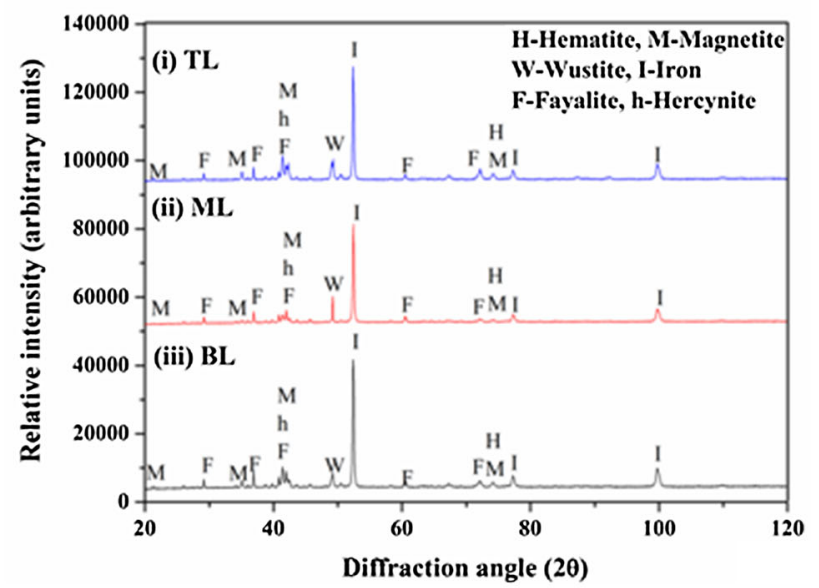

(b)

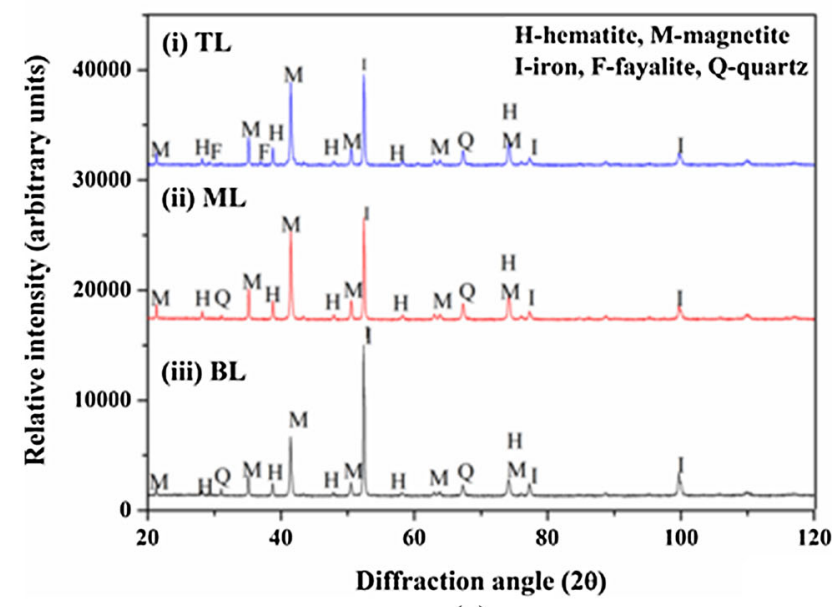

(c)

Fig. 8-XRD analysis of reduced sample with different $\mathrm{C} / \mathrm{Fe}_{2} \mathrm{O}_{3}$ molar ratios. (a) 1.33, (b) 1.66, (c) 3 .

higher compared to the pellets containing higher carbon because conductivity of coal $(\sim 0.2 \mathrm{~W} / \mathrm{m}-\mathrm{K})$ is significantly less than hematite $(\sim 18 \mathrm{~W} / \mathrm{m}-\mathrm{K})$. Thus, the low carbon-containing pellet will conduct heat comparatively faster and attain higher temperature quickly compared to pellets containing large amount coal. Higher temperature favors sintering and shrinkage. (3)
Again at low carbon-containing pellets, formation of liquid fayalite is more that wets pores and finally shrinks during solidification, leading to shrinkage.

\section{E. Phase analysis through $X R D$}

The layer-wise phase analysis of the reduced pellets by XRD for carbon-to-hematite molar ratio of 1.33 is shown in Figure 8(a). Figures 8(b) and (c) depicts the similar figure for the carbon-to-hematite molar ratio of 1.66 and 3 , respectively.

It is observed that at lower carbon content in the pellet, wustite (W) with some hercynite $\left(\mathrm{h}, \mathrm{FeAl}_{2} \mathrm{O}_{4}\right)$ are observed along with hematite $(\mathrm{H})$, magnetite $(\mathrm{M})$, fayalite $\left(\mathrm{F}, \mathrm{Fe}_{2} \mathrm{SiO}_{4}\right)$ in all layers in different proportions. In the case with higher carbon content $\left(\mathrm{C} / \mathrm{Fe}_{2} \mathrm{O}_{3}\right.$ ratio $=3$ ), there is no sign of wustite and hercynite. Also, fayalite is observed at the top layer only. It may be further noted that no residual carbon peak is observed which may be attributed due to its low amount and amorphous nature. The relative amount of various phases present in the reduced sample has been analyzed by Rietveld analysis using TOPAS software as presented in Table V.

In order to check the reliability of such phase quantification by Rietveld analysis, oxygen mass balance has been carried out based on the estimated phase constituents by Rietveld analysis, and the degree of reduction is calculated. The DOR calculated by Rietveld analysis closely matches with the experimental DOR with an error of \pm 7 pct. The oxygen balance also includes alumina and silica in the sample both before and after reduction. From Table V, it may be observed that the amounts of fayalite formed in the top layer of the reduced pellet in the case with $\mathrm{C} / \mathrm{Fe}_{2} \mathrm{O}_{3}$ of 1.33 and 1.66 are 18.2 and 22.4 , respectively, which are comparatively higher compared to 5.3 for the said ratio of 3 . Fayalite is liquid at the reduction temperature that blocks the gas passage. It also reduces the activity of $\mathrm{FeO}$ in fayalite that makes it difficult to be reduced by $\mathrm{CO}$. Also, there is a possibility that the carbon particles might get entrapped in the liquid slag phase and become difficult to be accessed for its gasification as well as for reduction resulting in lower DOR and DOM. It may be noted that in no case, the DOR exceeds 80 pct, which may be attributed to the liquid fayalite formation that halts the DOR beyond a certain limit. Some proper additives that restrict fayalite formation could be the scope for any future study. It is also observed that the amount of $\mathrm{FeO}$ formed in the bottom layer is comparatively lower as compared to top layer for the same degree of reduction. Also for the same degree of reduction, the amount of iron formed in the bottom layer is comparatively higher than that at the top layer. During cooling, since the top layer is directly exposed to the atmosphere, it gets cooled faster, whereas the lower layers cool at slower rate being shielded from open atmosphere at the top. During slow cooling, $\mathrm{FeO}$ decomposes as: ${ }^{[20]} 4 \mathrm{FeO}=\mathrm{Fe}_{3} \mathrm{O}_{4}+\mathrm{Fe}$ that results in higher iron and lower $\mathrm{FeO}$ content in the lower layers compared to the top layer. Effect of such decomposition is also observed in Figure 3, where the data from middle 


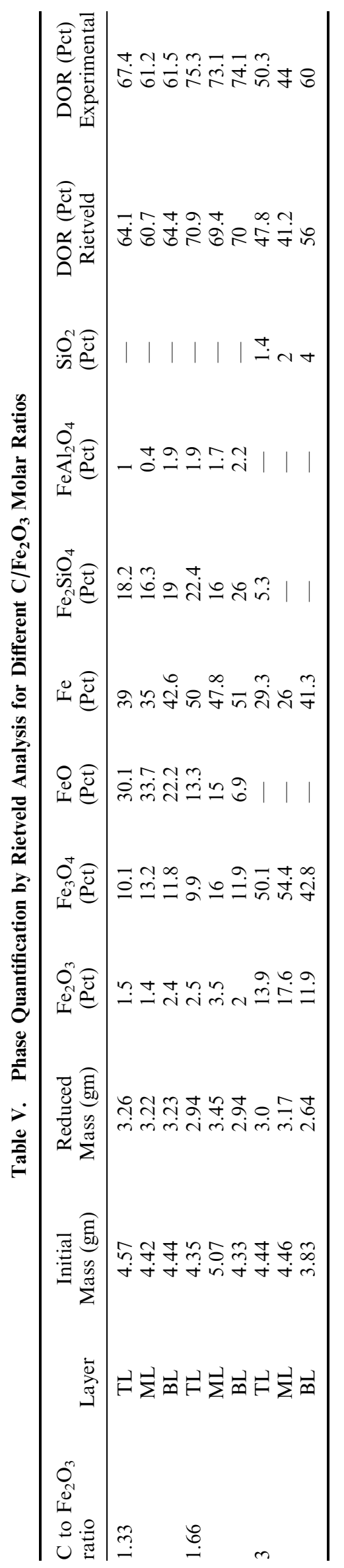

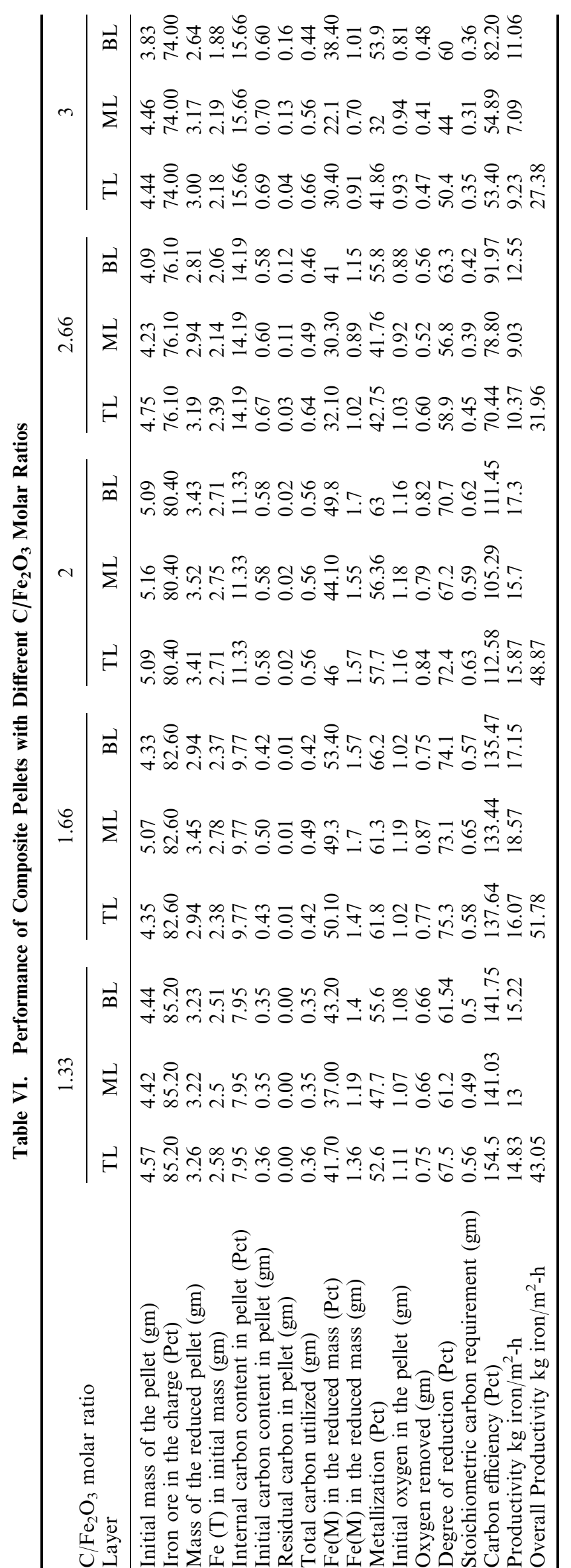

METALLURGICAL AND MATERIALS TRANSACTIONS B 


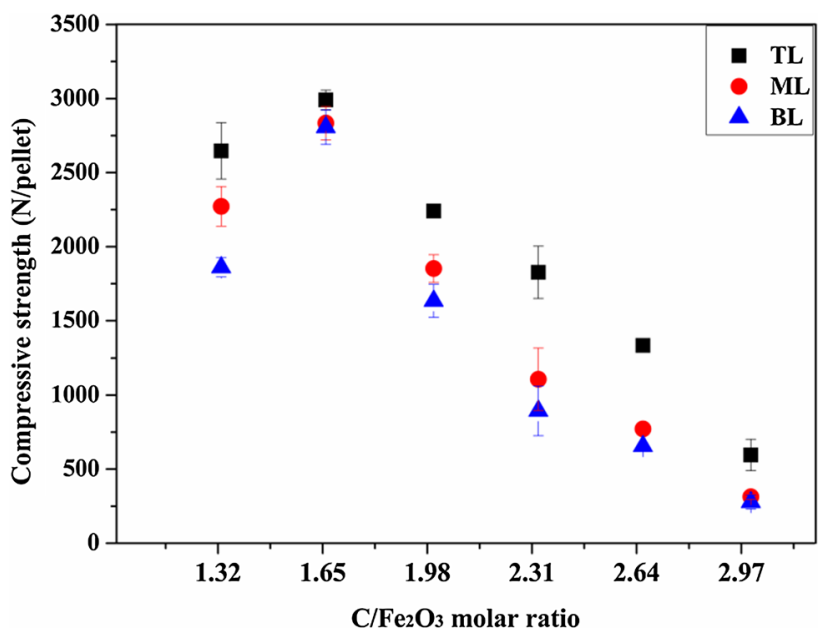

Fig. 9-Compressive strength of the reduced pellets with the variation in $\mathrm{C} / \mathrm{Fe}_{2} \mathrm{O}_{3}$ molar ratio.

and bottom layer were found to deviate away from the stoichiometric line to the data from top layer. The increase of magnetite at lower layers might also be attributed to such decomposition.

\section{F. Performance parameters}

In order to compare the process efficiency of different pellets with varying carbon contents, the following performance parameters have been calculated and compared. These parameters are the degree of reduction, metallization, carbon efficiency, and productivity. Carbon efficiency is defined as the stoichiometric carbon required to the actual carbon used in the pellet. The productivity is defined as the amount of metallic iron produced per unit area of hearth per unit time. The performance analysis with different $\mathrm{C} / \mathrm{Fe}_{2} \mathrm{O}_{3}$ molar ratios is shown in Table VI.

From Table VI, it is observed that the carbon efficiency is higher for lower $\mathrm{C} / \mathrm{Fe}_{2} \mathrm{O}_{3}$ ratio and is above 100 pct. 100 pet efficiency indicates that the product gas is fully $\mathrm{CO}$ and $\mathrm{O} / \mathrm{C}$ molar ratio is 1 and zero utilization of $\mathrm{CO}$ that has the potential to pick up one more ore oxygen atom. Carbon efficiency above 100 pct indicates better $\mathrm{CO}$ utilization, higher $\mathrm{O} / \mathrm{C}$ in the product gas and lower use of carbon than stoichiometric carbon required for hematite reduction by direct reduction (C/ $\mathrm{Fe}_{2} \mathrm{O}_{3}=3$ ). It is further noted that the carbon efficiency is higher in top layer compared to lower layers for lower carbon level $\left(\mathrm{C} / \mathrm{Fe}_{2} \mathrm{O}_{3}\right.$ ratio $\left.<2.33\right)$ and is maximum in bottom layer for high carbon levels $\left(\mathrm{C} / \mathrm{Fe}_{2} \mathrm{O}_{3}\right.$ ratio $>2.33$ ), which is consistent with the observation of reduction efficiency for these carbon levels. The productivity is maximum (about $52 \mathrm{~kg}$ metallic iron $/ \mathrm{h}-\mathrm{m}^{2}$ ) for $\mathrm{C} / \mathrm{Fe}_{2} \mathrm{O}_{3}$ molar ratio of 1.66 which is the optimum carbon level for the maximum degree of reduction in the present experimental condition. Productivity is also found to be higher at the bottom layer as compared to other layers for all carbon levels, which may be attributed to slow cooling and $\mathrm{FeO}$ decomposition to $\mathrm{Fe}$ compared to top layer. A productivity of $46-58 \mathrm{~kg}$ metallic iron $/ \mathrm{h}-\mathrm{m}^{2}$ was reported by Kakogawa Demonstration Plant (KDP) employing Fastmet process. Similarly, an optimum productivity of $36 \mathrm{~kg}$ metallic iron/ $\mathrm{h}-\mathrm{m}^{2}$ was reported for a pilot plant operating with Comet process. ${ }^{[21]}$ All these reported productivity data are consistent with the present experimental data.

The compressive strength of the reduced pellet is measured by using an Instron universal testing machine with a cross-head movement of $0.25 \mathrm{~mm} /$ minute. The variation of the compressive strength of the reduced pellets with the variation in $\mathrm{C} / \mathrm{Fe}_{2} \mathrm{O}_{3}$ molar ratio layer-wise is depicted in Figure 9.

It is observed that the compressive strength is the maximum for the reduced pellets with the $\mathrm{C} / \mathrm{Fe}_{2} \mathrm{O}_{3}$ molar ratio of 1.66 for all three layers and is around $3000 \mathrm{~N} /$ pellet. The pellet of such high strength can be effectively utilized in a blast furnace, or electric arc furnace (EAF) for subsequent reduction and melting. ${ }^{20]}$ The peak strength of the partially reduced pellet at this ratio may be attributed to more iron content, consolidation and fewer cracks in the pellets.

\section{CONCLUSIONS}

1. Reduction efficiency of the iron ore-coal composite pellet in multi-layer bed Rotary Hearth Furnace (RHF) has found to be significantly influenced by the carbon content in the pellets. Carbon content in the composite pellet at $\mathrm{C} / \mathrm{Fe}_{2} \mathrm{O}_{3}$ molar ratio of 1.66 that is much less than the stoichiometric value required for direct reduction of hematite to iron $(\mathrm{C} /$ $\mathrm{Fe}_{2} \mathrm{O}_{3}=3$ ) has been found to be optimum for maximum degree of reduction $(\sim 70 \mathrm{pct})$ when such pellets are reduced at $1523 \mathrm{~K}\left(1250{ }^{\circ} \mathrm{C}\right)$ for $20 \mathrm{~min}$ utes in the reduction zone at RHF.

2. Layer-wise study of reduction efficiency indicates that the bottom layer possesses higher degree of reduction as compared to the top and middle layer in high carbon-containing pellets $\left(\mathrm{C} / \mathrm{Fe}_{2} \mathrm{O}_{3}>2.33\right)$, whereas the top layer shows higher degree of reduction at comparatively lower carbon-containing pellets $(\mathrm{C} /$ $\mathrm{Fe}_{2} \mathrm{O}_{3}<$ of 2.33).

3. Carbon efficiency (defined as the stoichiometric carbon required to the actual carbon used in the pellet) is found to be higher than 100 pct at lower carbon levels in the pellets. Carbon efficiency of 154 pct is observed at lowest carbon level $\left(\mathrm{C} / \mathrm{Fe}_{2} \mathrm{O}_{3}=1.33\right)$ at the top layer. The carbon efficiency decreases to the order of 50 at higher carbon level in the pellet $(\mathrm{C} /$ $\mathrm{Fe}_{2} \mathrm{O}_{3}=3$ ).

4. Productivity defined as $\mathrm{kg}$ of iron produced per $\mathrm{m}^{2}$ of hearth area per hour is found to be maximum (52) at the optimum carbon level, i.e., at $\mathrm{C} / \mathrm{Fe}_{2} \mathrm{O}_{3}$ ratio of 1.66 .

5. The compressive strength of reduced pellets from all three layers with optimum carbon content is found to be $3000 \mathrm{~N} /$ pellet. Such high strength allows its utilization even in a blast furnace as an alternative feed.

6. A correlation between the degree of reduction and degree of metallization for all data presented in this article indicates a non-isothermal kinetics with the 
role of heat and mass transfer in the pellet as well as in the pellet bed.

\section{REFERENCES}

1. Y.K. Rao: Metall. Trans., 1971, vol. 2, pp. 1439-47.

2. R.J. Freuhan: Metall. Trans. B, 1977, vol. 8B, pp. 279-86.

3. N.S. Srinivasan and A.K. Lahiri: Metall. Trans. B, 1977, vol. 8B, pp. 175-78.

4. K. Otsuka and D. Kunii: J. Chem. Eng. Jpn., 1967, vol. 2, pp. 4650

5. F. Ajersch: Can. Metall. Quart., 1987, vol. 26, pp. 137-44.

6. N. Narcin, S. Aydin, and F. Dikec: Int. J. Miner. Process., 1995, vol. 43, pp. 49-59.

7. S.M. Jung: ISIJ Int., 2014, vol. 54, pp. 2933-35.

8. T. Sharma: Ironmaking Steelmaking, 1993, vol. 20, pp. 362-66.

9. C. Bryk and W.K. Lu: Ironmaking Steelmaking, 1986, vol. 13, pp. $70-75$.

10. E. Kasai, T. Kitajima, and T. Kawaguchi: ISIJ Int., 2000, vol. 40, pp. $842-49$.
11. E.T. Turkdogan and J.V. Vinters: Carbon, 1972, vol. 10, pp. $97-$ 111.

12. O.M. Fortini and R.J. Freuhan: Metall. Mat. Trans. B, 2005, vol. 36B, pp. 865-72.

13. Q. Wang, Z. Yang, J. Tian, W. Li, and J. Sun: Ironmaking Steelmaking, 1998, vol. 25, pp. 443-47.

14. T. Y. Huang, S. H. Liu, and G. H. Shiau: China Steel Technical Report No. 27, pp. 11-19, 2014

15. I. Sohn and R.J. Freuhan: Metall. Mater. Trans. B, 2006, vol. 37B, pp. 231-38.

16. S. Halder and R.J. Freuhan: Metall. Mater. Trans. B, 2008, vol. 39B, pp. 809-17.

17. P.C. Pradhan: Hand Book of Sponge Iron for Rotary Kiln, Sri R. N. Sahoo, Cuttack, 2003, pp. 131-32.

18. T. Sharma: Int. J. Miner. Process., 1993, vol. 39, pp. 299-311.

19. E. Takegoshi, Y. Hirasawa, S. Imura, and T. Shimazaki: Int. J. Thermophys., 1984, vol. 5, pp. 219-28.

20. A.K. Biswas: Principles of Blast Furnace Ironmaking, SBA Publications, Calcutta, 1981, pp. 68-206.

21. A. Chatterjee: Sponge Iron production by Direct Reduction of Iron Oxide, PHI Learning Private Limited, New Delhi, 2010, pp. 14852. 